\title{
Low temperature catalyst-assisted pyrolysis of polymer precursors to carbon
}

\author{
RAMYA ARAGA, SURESH KALI and CHANDRA S SHARMA* \\ Creative and Advanced Research Based On Nanomaterials (CARBON) Laboratory, Department of Chemical Engineering, \\ Indian Institute of Technology, Hyderabad, Kandi 502285, Telangana, India \\ *Author for correspondence (cssharma@iith.ac.in)
}

MS received 11 July 2016; accepted 21 March 2017; published online 15 November 2017

\begin{abstract}
The aim of this work is to study the pyrolysis of polymer precursors to carbon at lower temperatures using a catalyst. We have added different weight ratios of nickel acetate tetrahydrate (NiAc) and multi-walled carbon nanotubes (MWCNTs) as catalysts into two different precursors, polyacrylonitrile (PAN) and resorcinol-formaldehyde (RF), separately. PAN composite was stabilized whereas RF composite was dried under sub-critical conditions followed by pyrolysis carried out at different temperatures. To examine the effect of pyrolysis temperature and catalyst concentration, PAN-and RF-derived carbons were characterized by elemental analysis, X-ray diffraction, Raman spectroscopy, transmission electron microscopy, Fourier transform infrared spectrophotometer and small angle X-ray scattering, respectively. It was found that addition of NiAc facilitated similar carbon yield at much lower temperature than what was obtained without a catalyst. The addition of MWCNTs enhanced the crystallinity of carbon samples, which is otherwise possible only by higher heat treatment. This study clearly suggests adopting catalyst-assisted less energy intensive low temperature pyrolysis for polymer precursors to carbon with better yield as well as crystallinity.
\end{abstract}

Keywords. Polyacrylonitrile; resorcinol-formaldehyde; pyrolysis temperature; carbon yield; crystallinity.

\section{Introduction}

Carbon materials gained a wide range of applications because of the availability of several allotropes and its unique physiochemical properties [1,2]. Heat treatment is a process to convert the organic compounds into high-performance carbon. PAN is one of the most widely used polymer precursors for commercial carbon materials manufacturing including fibres, films and activated carbons [3-5]. To convert PAN into carbon, the precursor has to be first stabilized at 250 $300^{\circ} \mathrm{C}$ in oxygen atmosphere followed by high-temperature carbonization at more than $1000^{\circ} \mathrm{C}$. These carbons can be graphitized above $2000^{\circ} \mathrm{C}$ [6-8]. In recent years, a number of studies revealed that various carbon precursors were successfully graphitized at lower temperatures by adding the transition metals and carbon nanotubes (CNTs) as catalysts. The addition of catalysts minimizes the energy requirements for the graphitization process [9-13]. However, most of these studies were limited to graphitization of carbons above $900^{\circ} \mathrm{C}$, in the presence of a catalyst, to improve the crystallinity of carbon. Only very few studies are available on the low-temperature carbonization of PAN adding the metal particles and that too primarily focused on the removal of nitrogen from PAN by reducing the decomposition temperature $[14,15]$. Among the different polymers, PAN and resorcinol-formaldehyde (RF) organic gel were well studied because of their high carbon yield. Apart from carbon yield, RF organic gel is also identified as a widely used precursor to produce carbon xerogel, aerogel and cryogels with wide range of surface area and morphologies [1620] for their applications as electrodes in energy storage devices.

The present study deals with the catalytic carbonization of PAN and RF xerogel precursors at different temperatures by using nickel acetate tetrahydrate (NiAc) and multi-walled carbon nanotubes (MWCNTs) as catalysts. To understand the pyrolysis process and thereby properties of carbon material obtained, structural characterization tests such as $\mathrm{X}$-ray diffraction, Raman spectroscopy, transmission electron microscopy, Fourier transform infrared spectroscopy (FTIR) and small angle $\mathrm{X}$-ray scattering were carried out. It has been found that nickel particles after reduction were found to be more effective in the increase of carbon yield by eliminating the higher amounts of oxygen, whereas MWCNTs assisted in achieving a higher degree of crystallinity at a given temperature. 


\section{Experimental}

\subsection{Materials}

Polyacrylonitrile (average MW $=150,000$ ), N, N-Dimethyl formamide (DMF, 99.5\%), $\left(\mathrm{C}_{4} \mathrm{H}_{14} \mathrm{NiO}_{8}\right) \mathrm{NiAc}(98 \%)$ and sodium carbonate $\left(\mathrm{Na}_{2} \mathrm{CO}_{3}, 99.5 \%\right)$ were purchased from Sigma-Aldrich, India. Resorcinol (99\% purity) and formaldehyde $(37 \% \mathrm{w} / \mathrm{v}$; stabilized with $10 \%$ methanol) were purchased from Merck, India. MWCNTs (with carbon purity of $>95 \%$, number of walls 3-15) were purchased from Reinste Nano Ventures Pvt. Ltd., India.

\subsection{Preparation of polymer/catalyst composites}

Polyacrylonitrile ( $8 \mathrm{wt} \%$ ) was mixed in DMF by using magnetic stirrer at $65^{\circ} \mathrm{C}$ for $30 \mathrm{~min}$ to obtain the uniform colourless polymer solution as reported by Zussman et al [21]. Three different concentrations of catalysts $(0.5,2$ and $10 \mathrm{wt} \%)$ were used to prepare the composites. In the case of NiAc addition, a magnetic stirrer was used to mix the catalyst because a significant amount of salt can be dissolved in the polymer solution without precipitation. However, the dispersion of MWCNTs in polymer matrix is difficult and therefore MWCNTs were first added to the DMF solvent and sonicated for $30 \mathrm{~min}$ using the probe sonicator to get the homogeneous solution. Later PAN polymer was dissolved in the stable suspension of MWCNT to achieve the uniformly dispersed polymer solution [22]. The prepared composite solutions were cast into glass Petri dishes followed by stabilization under oxidative atmosphere at $250^{\circ} \mathrm{C}$ for $2 \mathrm{~h}$; oven temperature was raised to stabilization temperature with the ramp rate of $1^{\circ} \mathrm{C} \mathrm{min}^{-1}$.

$\mathrm{RF}$ sol was prepared by mixing resorcinol with formaldehyde, using deionized (DI) water as solvent and $\mathrm{Na}_{2} \mathrm{CO}_{3}$ as catalyst (with a molar ratio of $\mathrm{R}: \mathrm{F}: \mathrm{W}: \mathrm{C}=1: 2: 27.03: 0.04$ ) in following the procedure reported by Kakunuri et al [20]. This mixture was stirred for $30 \mathrm{~min}$ to get a clear solution and a different $w t \%$ of the catalyst was added to prepare a uniform solution before the gelation process. Thus, the obtained solution was stirred until a homogeneous solution is obtained. Furthermore, the solution was dried at room temperature for $24 \mathrm{~h}$ followed by another $24 \mathrm{~h}$ at sub-critical conditions to obtain the dried RF xerogel.

\subsection{Carbonization}

Stabilized PAN and dried RF xerogel samples were pyrolysed in the tubular high-temperature furnace (Nabertherm GMBH) at different temperatures $\left(400,500,600,700,800\right.$ and $900^{\circ} \mathrm{C}$, respectively) in high purity nitrogen $\left(\mathrm{N}_{2}\right)(99.99 \%)$ atmosphere. The rate of heating was maintained as $5^{\circ} \mathrm{C} \mathrm{min}^{-1}$ and when it reached the carbonization temperature, it was kept constant for $2 \mathrm{~h}$. The pyrolysed samples were labelled as $\mathrm{P}-x$ Cat-Temp, where $\mathrm{P}$ and Cat represents the corresponding polymer and catalyst used, $x$ represents the weight percentage of the catalyst and Temp is corresponding to pyrolysis temperature in degree Celsius, respectively. Carbon samples derived from polymer solutions without any catalyst additives named as P-Temp were also prepared for reference.

\subsection{Characterization}

Elemental composition of as-prepared carbon samples was examined by CHNS/O analyser (FLASH 2000, Thermo Scientific). Structural characterizations were carried out using an X-ray diffractometer (XRD) (PANalytical) with $\mathrm{Cu} \mathrm{K} \alpha$ radiation $(0.154 \mathrm{~nm})$; whereas Raman spectra were recorded with a $532 \mathrm{~nm}$ excitation on the Raman spectrometer (Senterra, Bruker). Furthermore, microstructures of the carbonized samples were investigated using high-resolution transmission electron microscopy (HRTEM) (FEI TecnaiG2S-Twin) at the accelerating voltage of $200 \mathrm{kV}$. Functional groups of the stabilized and carbonized samples were studied by Fourier transform infrared spectroscopy (FTIR) (Tensor 37, Bruker). To estimate the radius of gyration and surface area, small angle $\mathrm{X}$-ray scattering (SAXS) (SAXess, Anton-Paar) system with $\mathrm{Cu} \mathrm{K} \alpha$ radiation was used.

\section{Results and discussions}

\subsection{Elemental analysis}

Elemental composition of each set of samples pyrolysed at different temperatures is summarized in table 1. Carbon (C), hydrogen $(\mathrm{H})$ and nitrogen $(\mathrm{N})$ percentage of samples were analysed from the gases, which were evolved for respective pyrolysed samples. The oxygen content was calculated by subtracting the $\mathrm{C}, \mathrm{H}$ and $\mathrm{N}$ from total content, which is $100 \%$. In case of carbon samples pyrolysed using a catalyst, the remaining amount of nickel (during pre-oxidation at $250^{\circ} \mathrm{C}$ $\mathrm{NiAc}$ could be converted into nickel oxide (NiO) and through the pyrolysis $\mathrm{NiO}$ was completely converted to metallic nickel [23]), residual carbon (obtained due to the decomposition of acetate groups) and CNT were subtracted from $\mathrm{P}-x$ Cat-Temp samples to estimate the amount of oxygen present. Figure 1 shows the graphical representation of carbon composition of the PAN precursor (as mentioned in table 1) pyrolysed at various temperatures with and without catalysts.

For only PAN-derived carbon samples (with no added catalyst), the carbon percentage is increased from 55.12 to 78.7 as temperature increased from 400 to $900^{\circ} \mathrm{C}$. At $400^{\circ} \mathrm{C}$, the percentage value of carbon is slightly higher than the MWCNT doped sample. For PAN- $0.5 \%$ NiAc-derived carbons, the variation is more and a higher carbon percentage was achieved at maximum temperature than the remaining set of samples. Quantity of $70 \%$ of carbon was obtained at $800^{\circ} \mathrm{C}$ for PAN; whereas the same amount was achieved at $500^{\circ} \mathrm{C}$ only in PAN- $0.5 \%$ NiAc. Hydrogen wt $\%$ is high for PAN- $0.5 \%$ NiAc$400^{\circ} \mathrm{C}$ because of the presence of acetate groups in NiAc. As the temperature increases, the acetate groups decomposed and hydrogen content was reduced from 5.54 to $3.01 \%$ [23]. 
Table 1. Elemental composition of PAN and PAN/catalyst-derived samples.

\begin{tabular}{|c|c|c|c|c|}
\hline \multirow[b]{2}{*}{ Sample } & \multicolumn{4}{|c|}{ Composition (wt\%) } \\
\hline & $\mathrm{C}$ & $\mathrm{H}$ & $\mathrm{N}$ & $\mathrm{O}$ \\
\hline $\mathrm{PAN}-400^{\circ} \mathrm{C}$ & 55.12 & 4.19 & 21.99 & 18.7 \\
\hline $\mathrm{PAN}-500^{\circ} \mathrm{C}$ & 59.56 & 2.91 & 21.05 & 16.48 \\
\hline $\mathrm{PAN}-600^{\circ} \mathrm{C}$ & 62.65 & 2.15 & 19.3 & 15.9 \\
\hline $\mathrm{PAN}-700^{\circ} \mathrm{C}$ & 67.56 & 1.59 & 19.2 & 11.65 \\
\hline $\mathrm{PAN}-800^{\circ} \mathrm{C}$ & 71.51 & 1.24 & 16.33 & 10.92 \\
\hline $\mathrm{PAN}-900^{\circ} \mathrm{C}$ & 78.7 & 0.99 & 10.41 & 9.9 \\
\hline $\mathrm{PAN}-0.5 \% \mathrm{NiAc}-400^{\circ} \mathrm{C}$ & 60.79 & 5.54 & 22.46 & 5.01 \\
\hline $\mathrm{PAN}-0.5 \% \mathrm{NiAc}-500^{\circ} \mathrm{C}$ & 70.41 & 3.96 & 21.41 & 3.59 \\
\hline $\mathrm{PAN}-0.5 \% \mathrm{NiAc}-600^{\circ} \mathrm{C}$ & 71.48 & 3.82 & 21.29 & 1.61 \\
\hline $\mathrm{PAN}-0.5 \% \mathrm{NiAc}-700^{\circ} \mathrm{C}$ & 72.11 & 3.44 & 19.69 & 0.97 \\
\hline $\mathrm{PAN}-0.5 \% \mathrm{NiAc}-800^{\circ} \mathrm{C}$ & 72.46 & 3.18 & 16.83 & 0.55 \\
\hline PAN- $0.5 \% \mathrm{NiAc}-900^{\circ} \mathrm{C}$ & 85.53 & 3.01 & 9.85 & 0.4 \\
\hline PAN- $0.5 \%$ MWCNT- $400^{\circ} \mathrm{C}$ & 54.52 & 3.62 & 20.12 & 21.74 \\
\hline PAN-0.5\%MWCNT- $500^{\circ} \mathrm{C}$ & 55.22 & 2.71 & 19.31 & 22.76 \\
\hline PAN-0.5\%MWCNT- $600^{\circ} \mathrm{C}$ & 57.69 & 1.9 & 19.01 & 21.4 \\
\hline PAN- $0.5 \%$ MWCNT- $700^{\circ} \mathrm{C}$ & 58.03 & 1.58 & 17.58 & 22.82 \\
\hline PAN- $0.5 \%$ MWCNT- $800^{\circ} \mathrm{C}$ & 58.91 & 1.27 & 15.33 & 24.49 \\
\hline PAN-0.5\%MWCNT- $900^{\circ} \mathrm{C}$ & 60.65 & 1.04 & 8.64 & 29.67 \\
\hline
\end{tabular}

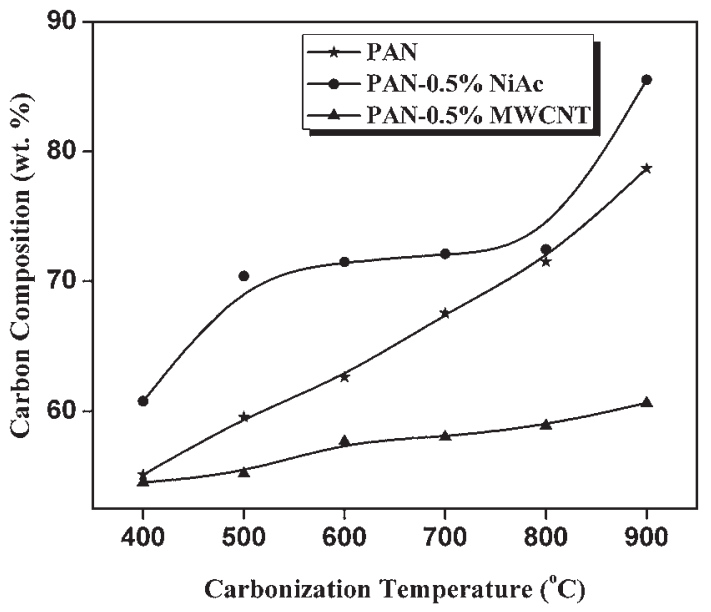

Figure 1. Carbon composition of PAN, PAN-0.5\% NiAc and PAN$0.5 \%$ MWCNT-derived carbons.

The hydrogen content in MWCNT-added samples is less than pure PAN because the thermal conductivity of CNT helped in the dehydrogenation process during the stabilization. However, not much difference was observed in the nitrogen composition for all samples (with and without catalyst) that indicate the incomplete denitrogenation due to less stabilization temperature. The higher stabilization and carbonization temperatures with less ramp rate may help in lower nitrogen content [8]. A higher percentage of oxygen is observed in PAN-0.5\% MWCNT-derived samples, due to the functionalization of MWCNT during the stabilization process.

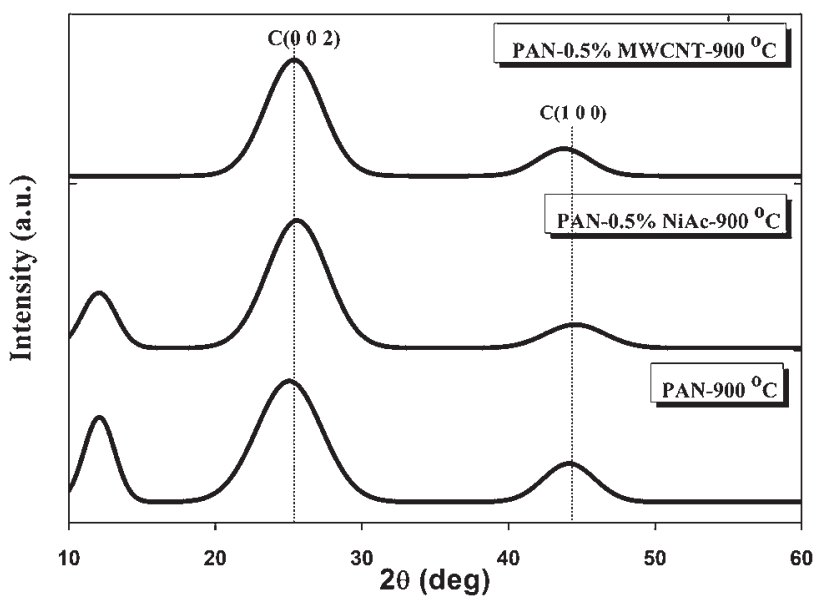

Figure 2. XRD spectrum of PAN, PAN- $0.5 \% \mathrm{NiAc}$ and PAN- $0.5 \%$ MWCNT-derived carbons.

Table 2. Structural parameters of XRD for PAN and PAN/ catalyst-derived carbons.

\begin{tabular}{lccc}
\hline Sample & $\mathrm{d}_{(002)}(\AA)$ & $L_{\mathrm{c}}(\AA)$ & $L_{\mathrm{c}} / \mathrm{d}_{(002)}$ \\
\hline PAN-900 ${ }^{\circ} \mathrm{C}$ & 3.55 & 15.7 & 4.42 \\
$\mathrm{PAN}-0.5 \% \mathrm{NiAc}-900^{\circ} \mathrm{C}$ & 3.54 & 18.2 & 5.14 \\
$\mathrm{PAN}-0.5 \% \mathrm{MWCNT}-900^{\circ} \mathrm{C}$ & 3.48 & 21.4 & 6.15 \\
\hline
\end{tabular}

For RF and RF/catalyst-derived samples, similar results were observed in terms of carbon, hydrogen and oxygen content (see supplementary information for details). Detailed 
compositions of samples pyrolysed at different temperatures are described in supplementary table S1. The higher catalyst compositions were also prepared ( 2 and $10 \mathrm{wt} \%$ ), in which carbon amount was reduced from 2 to $20 \%$ of plain RF-derived carbons. However, the carbon content at higher $\mathrm{wt} \%$ of catalyst was not found to be higher compared to low catalyst content samples. This can be attributed to agglomeration of the catalyst at higher concentrations, which reduced the effective activity of the catalyst at a higher concentration $(>2 \mathrm{wt} \%)$.

The carbon wt\% has been improved up to the value of 8.7 for both PAN- and RF-derived carbons by adding NiAc to the polymer matrix. Addition of MWCNT did not significantly assist in achieving the higher amount of carbon, but it is advantageous in the graphitization process.

\subsection{Structural characterizations}

Figure 2 shows the X-ray diffraction patterns of PAN and PAN/catalyst composite derived carbons that exhibited broad peaks at $2 \theta=25^{\circ}$ and $44^{\circ}$ corresponds to $\left(\begin{array}{lll}0 & 0 & 2\end{array}\right)$ and $\left(\begin{array}{lll}1 & 0 & 0\end{array}\right)$ reflections of carbon [12]. The presence of ( 100 l 0 ) plane along with a peak at $12.5^{\circ}$ in PAN- $900^{\circ} \mathrm{C}$ and PAN- $0.5 \% \mathrm{NiAc}-900^{\circ} \mathrm{C}$ indicate that the carbonized samples contain both graphitic and disordered carbon [24].
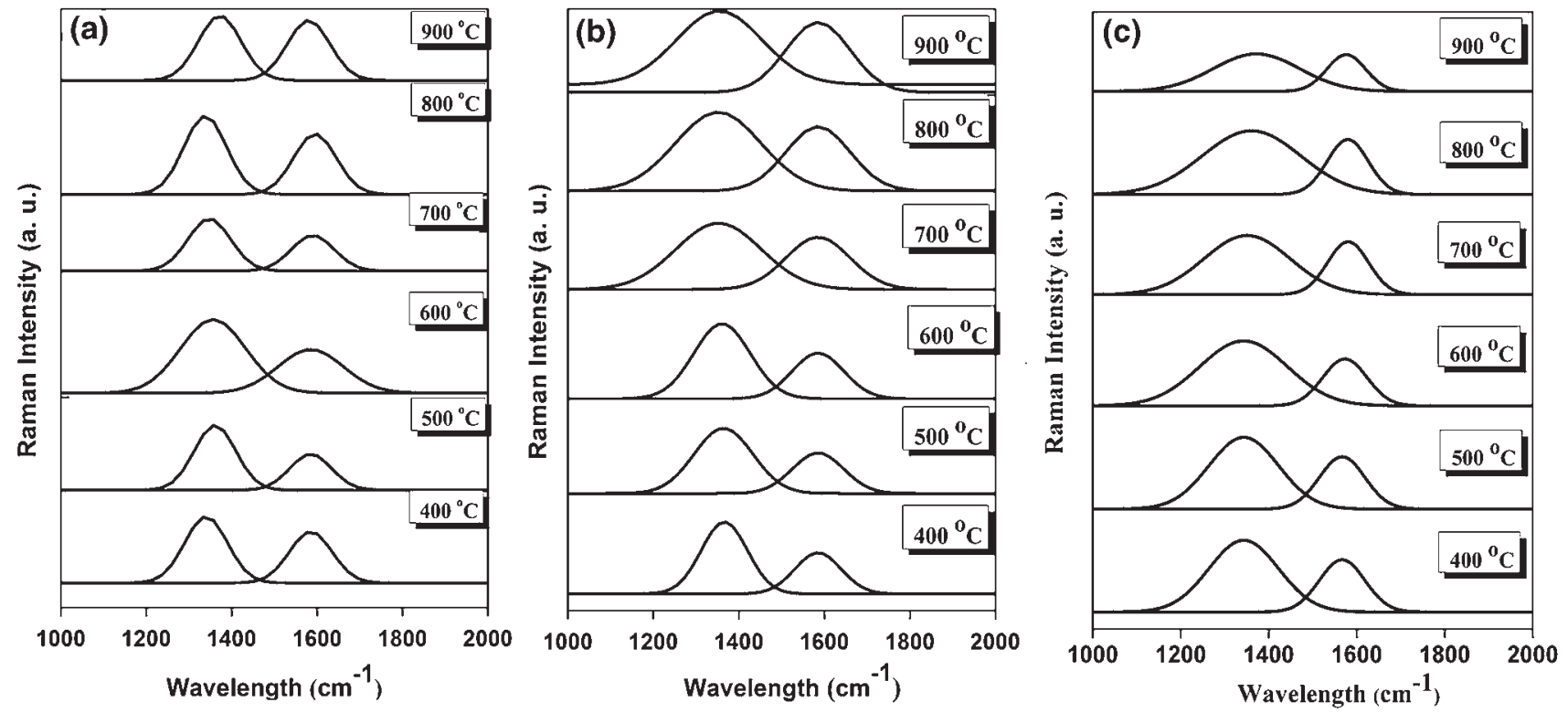

Figure 3. Raman spectra for carbons derived from (a) PAN, (b) PAN-0.5\% NiAc and (c) PAN-0.5\% MWCNT.
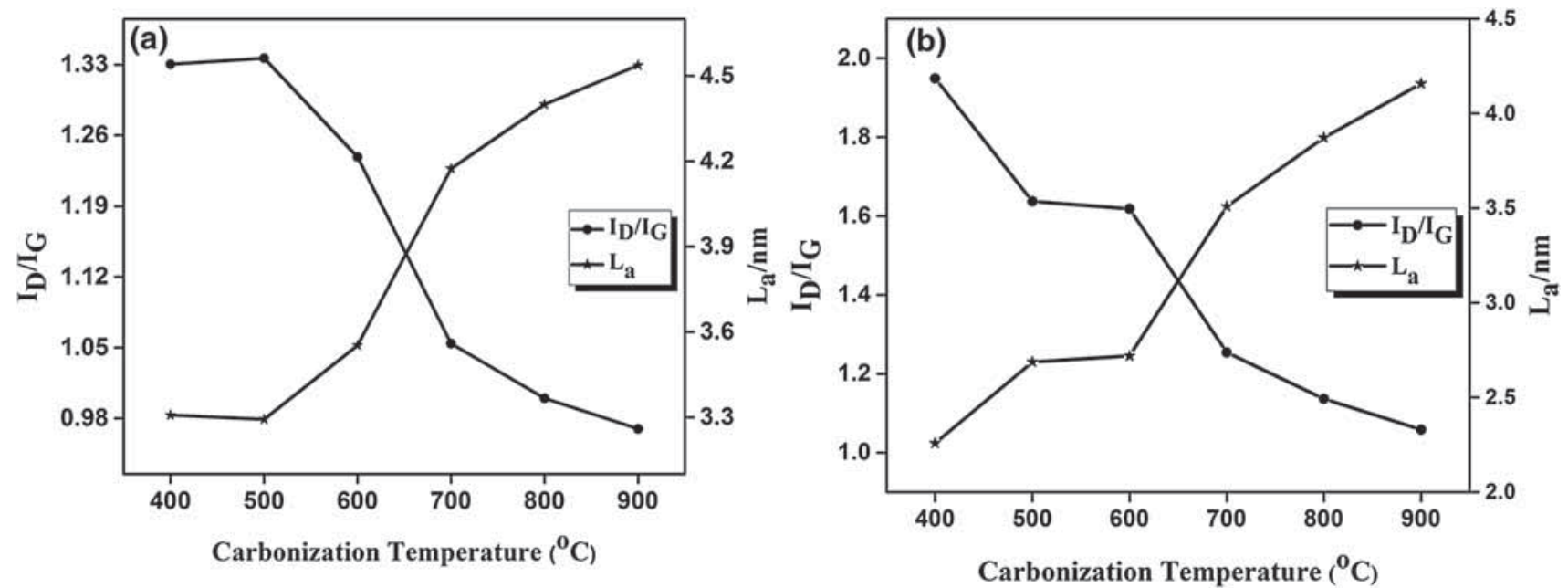

Figure 4. Intensity ratio and graphite crystallite size for carbons derived from (a) PAN-0.5\% NiAc and (b) PAN-0.5\% MWCNT. 

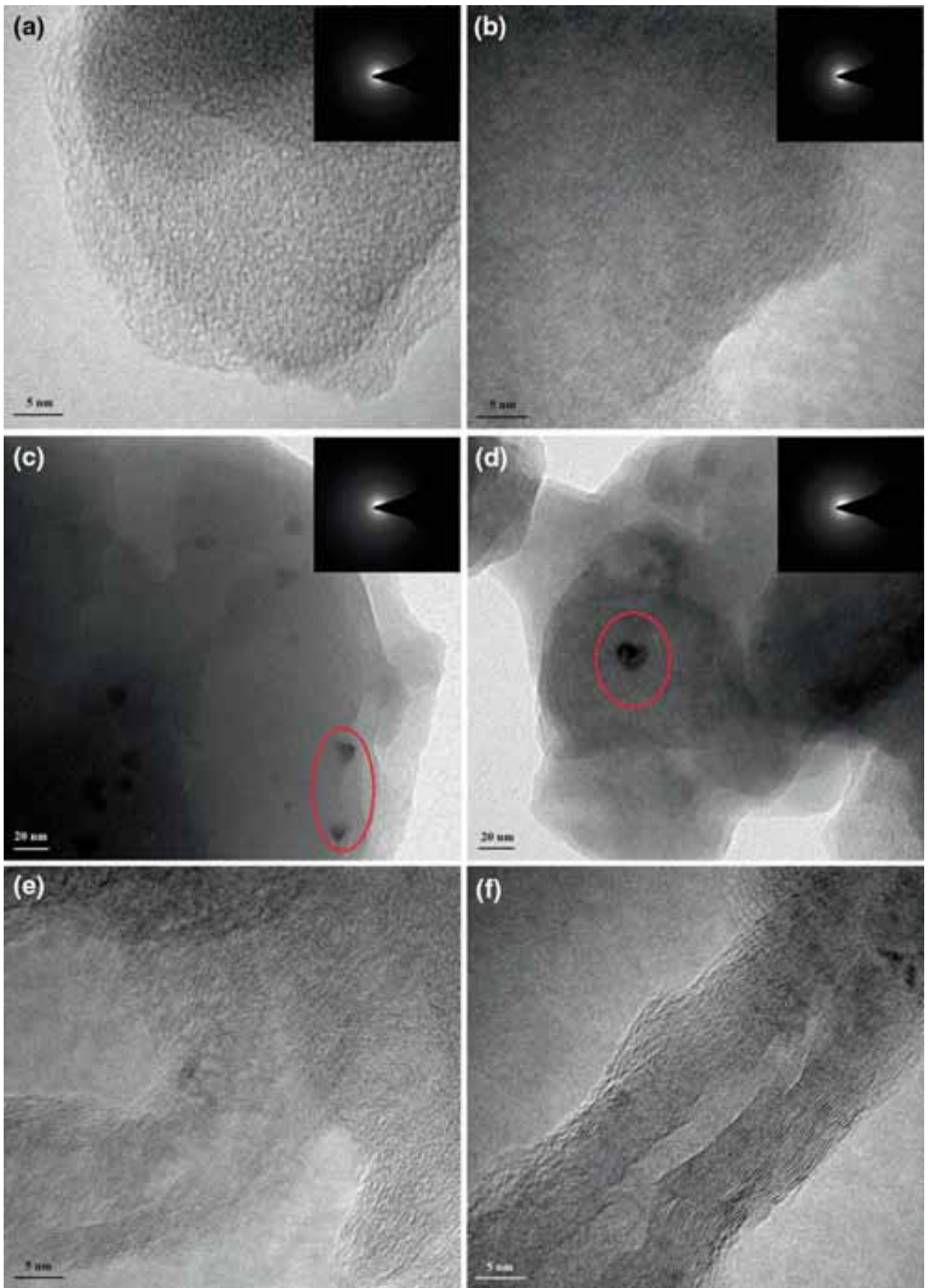

Figure 5. HRTEM micrographs of (a) PAN $-400^{\circ} \mathrm{C}$, (b) $\mathrm{PAN}-900^{\circ} \mathrm{C},(\mathbf{c}) \mathrm{PAN}-0.5 \% \mathrm{NiAc}-400^{\circ} \mathrm{C}$, (d) PAN- $0.5 \% \mathrm{NiAc}-900^{\circ} \mathrm{C}$, (e) PAN- $0.5 \%$ MWCNT- $400^{\circ} \mathrm{C}$ and (f) PAN- $0.5 \%$ MWCNT- $900^{\circ} \mathrm{C}$. The insets of $\mathbf{a}, \mathbf{b}, \mathbf{c}$ and $\mathbf{d}$ are corresponding SAED patterns of carbonized samples.

The disordered peak $\left(12.5^{\circ}\right)$ is absent in the XRD pattern of PAN- $0.5 \%$ MWCNT- $900^{\circ} \mathrm{C}$ sample that indicates the existence of graphitized carbonaceous structures. The addition of MWCNTs to the polymer has facilitated the formation of the graphene layers in the vicinity of the MWCNT during the heat treatment and ended with graphitic structures as also summarized in table 2.
Table 2 shows that both interlayer spacing $\left(\mathrm{d}_{(002)}\right)$ and crystallite size $\left(L_{\mathrm{c}}\right)$ values significantly varied by the addition of a catalyst. Interlayer spacing $\mathrm{d}_{(002)}$ was calculated from Bragg's law and $L_{\mathrm{c}}$ from Scherrer's formula. There was a decrease in $\mathrm{d}_{(002)}$ from 3.55 to $3.48 \AA$ and an increase in $L_{\mathrm{c}}$ from 15.7 to $21.4 \AA$ indicating the addition of CNT, which assisted in the graphitization of as-prepared carbons 

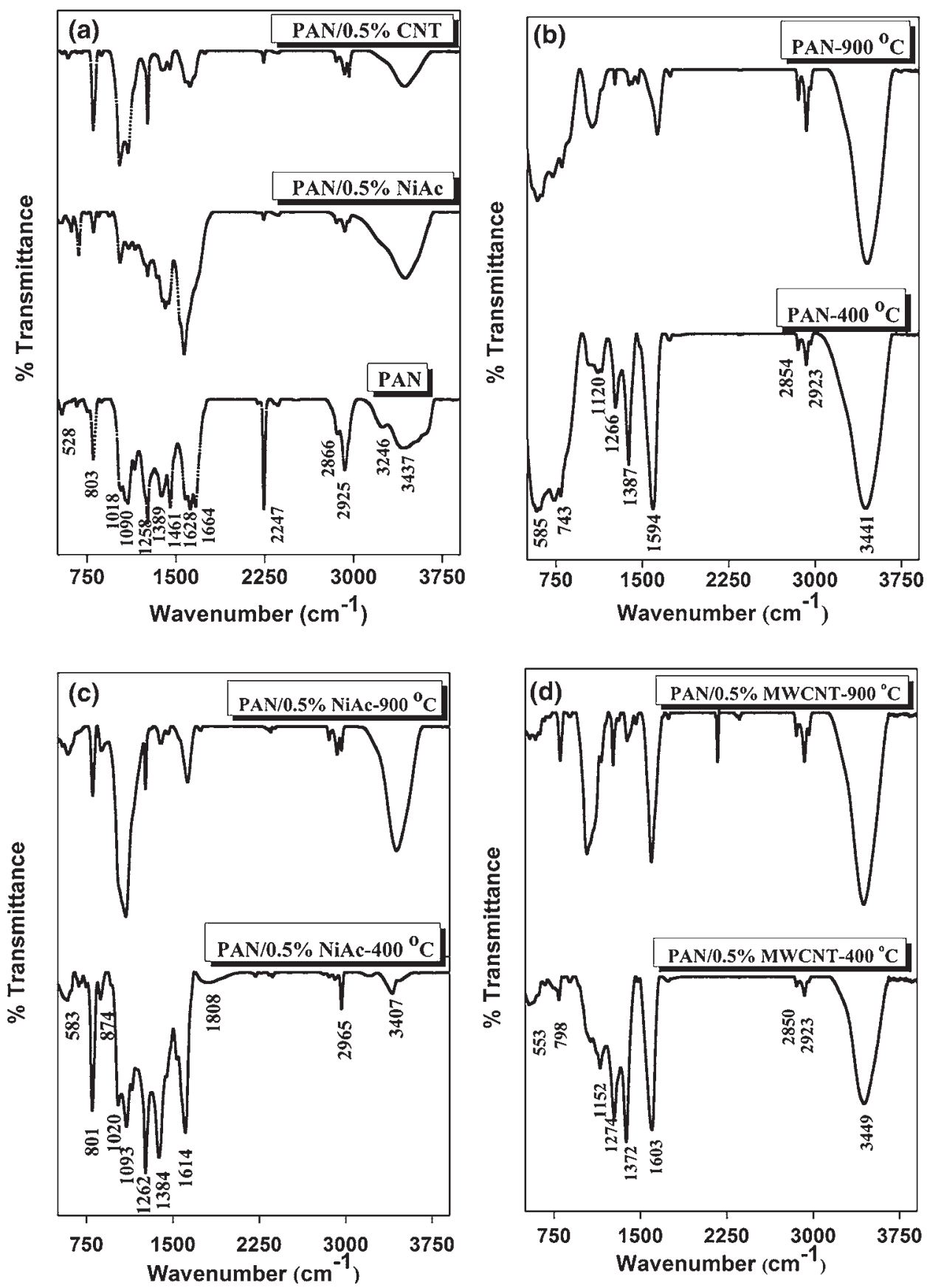

Figure 6. FTIR spectra of (a) stabilized, (b) PAN, (c) PAN-0.5\% NiAc and (d) PAN-0.5\% MWCNT carbonized at 400 and $900^{\circ} \mathrm{C}$.

[25], without significantly improving the carbon yield. This is further illustrated in Raman spectra below.

Figure 3 displays two characteristic peaks around $1580 \mathrm{~cm}^{-1}$ (G band) and $1350 \mathrm{~cm}^{-1}$ (D band) in the deconvoluted Raman spectra of as-prepared carbons. G-peak characterizes the highly ordered graphite crystallite structures, whereas D-peak is associated with disorders and defects of graphitic domains that exist in the carbonaceous material [12].
From Raman spectra of only PAN-derived carbons, the intensity of increase in G-peak was relatively less with the increasing heat treatment temperature when compared with D-peak. However, in PAN-0.5\% NiAc sample D-peak became broader at higher temperatures and this broadness is much significant from $600^{\circ} \mathrm{C}$ in PAN-0.5\% MWCNTderived carbons. This behaviour was more clearly understood while further calculating the in-planar crystallite width $\left(L_{\mathrm{a}}\right)$. 

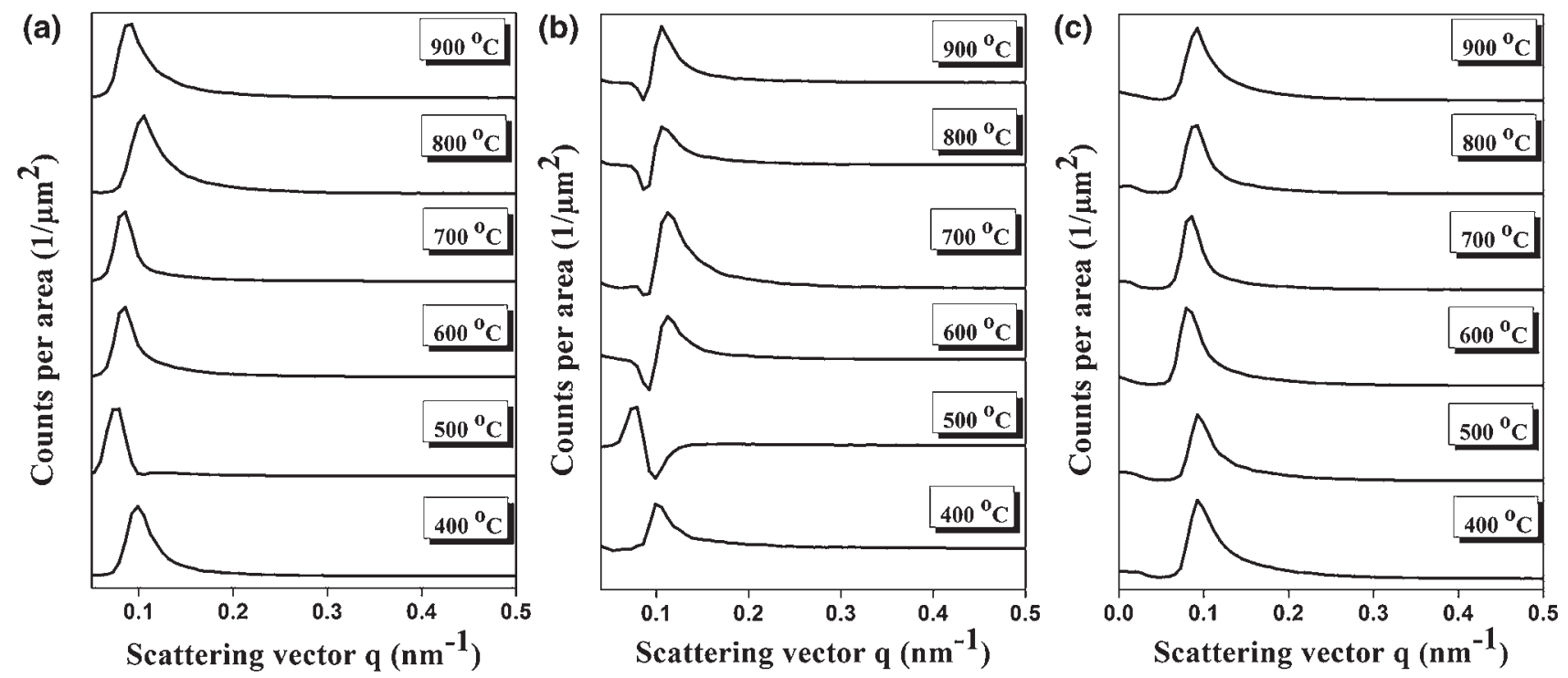

Figure 7. Small angle X-ray scattering curves of (a) PAN, (b) PAN-0.5\% NiAc and (c) PAN-0.5\% MWCNT-derived carbons.

Intensity ratio $\left(I_{\mathrm{D}} / I_{\mathrm{G}}\right)$ and in-planar crystallite width $\left(L_{\mathrm{a}}\right)$ were calculated for catalyst added samples and reported in figure 4. For PAN/NiAc samples $L_{\mathrm{a}}$ was increased from 3.31 to 4.54 and $I_{\mathrm{D}} / I_{\mathrm{G}}$ was reduced from 1.33 to 0.9 with an increase in the carbonization temperature. In case of PAN/MWCNT samples, $L_{\mathrm{a}}$ was increased from 2.26 to 4.16 and $I_{\mathrm{D}} / I_{\mathrm{G}}$ was reduced from 1.95 to 1.06 , respectively. This indicates that along with MWCNT, crystal planes of Ni also played a key role in producing the ordered carbon.

Figure 5 shows the HRTEM micrographs of different samples carbonized at temperatures of 400 and $900^{\circ} \mathrm{C}$. Selected-area electron diffraction (SAED) patterns of PAN and PAN/nickel acetate-derived materials without any bright spots reveal the amorphous nature of carbon. However, little arrangement around the catalyst particles can be observed for the samples pyrolysed at $900^{\circ} \mathrm{C}$. In case of PAN- $0.5 \%$ MWCNT $-400^{\circ} \mathrm{C}$ sample, no enhancement in the crystallite size is observed, but for PAN- $0.5 \%$ MWCNT- $900^{\circ} \mathrm{C}$, the size of crystallite domain in carbon matrix increased because of the arrangement of graphene layers at the neighbourhood of added CNTs as shown in figure 4f. Interlayer spacing measured from the TEM image is $0.34 \mathrm{~nm}$ and is found to be consistent with the interlayer spacing calculated from XRD analysis.

\subsection{Functional group characterization}

Figure 6 shows FTIR spectra obtained for stabilized and carbonized PAN as well as PAN/catalyst composites. Significant changes have been observed in the characteristic absorption peaks of carbonized samples. Most of the strong absorption peaks that appear in spectra is related to the existence of $\mathrm{C}=\mathrm{C}, \mathrm{C} \equiv \mathrm{N}, \mathrm{O}-\mathrm{H}, \mathrm{C}-\mathrm{H}, \mathrm{C}-\mathrm{O}, \mathrm{C}-\mathrm{N}$ and $\mathrm{N}-\mathrm{H}$, respectively.
Stabilized PAN film shows prominent peaks at $3437 \mathrm{~cm}^{-1}$ and $3246 \mathrm{~cm}^{-1}(\mathrm{O}-\mathrm{H}$ stretch$), 2925 \mathrm{~cm}^{-1}$ and $2866 \mathrm{~cm}^{-1}$ (-CH stretch), $2247 \mathrm{~cm}^{-1}\left(\mathrm{C} \equiv \mathrm{N}\right.$ stretch), $1664 \mathrm{~cm}^{-1}(\mathrm{C}=\mathrm{C}$ stretch), $1628 \mathrm{~cm}^{-1}$ (N-H bend), $1461 \mathrm{~cm}^{-1}$ and $803 \mathrm{~cm}^{-1}$ (C-H bend), $1258 \mathrm{~cm}^{-1}$ (C-O stretch), 1090 and $1018 \mathrm{~cm}^{-1}$ (C-N stretch) $[7,26]$. For catalyst-added samples most of the peak intensities largely decreased and some peaks completely disappeared. $\mathrm{C} \equiv \mathrm{N}, \mathrm{O}-\mathrm{H}$ (present at $3246 \mathrm{~cm}^{-1}$ ) and $\mathrm{C}-\mathrm{H}$ peaks almost disappeared in PAN/NiAc or MWCNT stabilized samples, indicating that only PAN was not completely stabilized. However, the same has been achieved at the same temperature by adding the catalyst.

On the other hand, even after carbonization it was observed that the presence of absorption frequencies for $\mathrm{O}-\mathrm{H}, \mathrm{C}-\mathrm{H}$ and $\mathrm{C}-\mathrm{O}$ and its intensities reduced significantly at $900^{\circ} \mathrm{C}$ carbonization temperature. Nitrile functional group intensities have been observed to be higher even after carbonization at $900^{\circ} \mathrm{C}$, indicating that this pyrolysis temperature is not sufficient enough to form the pure carbon structure.

\subsection{SAXS analysis}

Background corrected small angle X-ray scattering curves of prepared carbons are shown in figure 7. SAXS studies were performed with a point collimation block and kapton foil was used as a window material for these powder samples because of its transparency towards X-rays. Data were recorded on an image plate detector for $20 \mathrm{~min}$ with a sampleto-detector distance of $261.2 \mathrm{~mm}$. All measured data were integrated to produce the one-dimensional scattering and subtracted from background scattering. Scattering intensity of samples is expressed as a function of the scattering vector, q.

To the obtained SAXS profiles, guinier and invariant analysis were applied to estimate radius of gyration $\left(R_{\mathrm{g}}\right)$ and surface 
Table 3. Structural parameters of SAXS for PAN and PAN/ catalyst-derived carbons.

\begin{tabular}{|c|c|c|}
\hline Sample & $\begin{array}{l}\text { Radius of gyra- } \\
\text { tion } R_{\mathrm{g}}(\mathrm{nm})\end{array}$ & $\begin{array}{c}\text { Surface area per } \\
\text { volume }\left(\mathrm{m}^{2} \mathrm{~cm}^{-3}\right)\end{array}$ \\
\hline $\mathrm{PAN}-400^{\circ} \mathrm{C}$ & $3.99 \pm 0.33$ & 207 \\
\hline $\mathrm{PAN}-500^{\circ} \mathrm{C}$ & $3.79 \pm 0.44$ & 362 \\
\hline $\mathrm{PAN}-600^{\circ} \mathrm{C}$ & $2.44 \pm 0.29$ & 396 \\
\hline $\mathrm{PAN}-700^{\circ} \mathrm{C}$ & $2.22 \pm 0.16$ & 507 \\
\hline $\mathrm{PAN}-800^{\circ} \mathrm{C}$ & $2.10 \pm 0.44$ & 519 \\
\hline PAN- $900^{\circ} \mathrm{C}$ & $1.84 \pm 0.22$ & 535 \\
\hline $\mathrm{PAN}-0.5 \% \mathrm{NiAc}-400^{\circ} \mathrm{C}$ & $3.18 \pm 0.33$ & 457 \\
\hline $\mathrm{PAN}-0.5 \% \mathrm{NiAc}-500^{\circ} \mathrm{C}$ & $4.20 \pm 0.20$ & 475 \\
\hline $\mathrm{PAN}-0.5 \% \mathrm{NiAc}-600^{\circ} \mathrm{C}$ & $4.63 \pm 0.27$ & 459 \\
\hline $\mathrm{PAN}-0.5 \% \mathrm{NiAc}-700^{\circ} \mathrm{C}$ & $3.60 \pm 0.30$ & 445 \\
\hline $\mathrm{PAN}-0.5 \% \mathrm{NiAc}-800^{\circ} \mathrm{C}$ & $3.12 \pm 0.30$ & 332 \\
\hline $\mathrm{PAN}-0.5 \% \mathrm{NiAc}-900^{\circ} \mathrm{C}$ & $3.11 \pm 0.24$ & 220 \\
\hline PAN- $0.5 \%$ MWCNT $-400^{\circ} \mathrm{C}$ & $1.82 \pm 0.17$ & 219 \\
\hline PAN- $0.5 \%$ MWCNT- $500^{\circ} \mathrm{C}$ & 1.710 .17 & 366 \\
\hline PAN- $0.5 \%$ MWCNT- $600^{\circ} \mathrm{C}$ & $1.66 \pm 0.22$ & 290 \\
\hline PAN-0.5\% MWCNT- $700^{\circ} \mathrm{C}$ & $2.08 \pm 0.14$ & 325 \\
\hline PAN- $0.5 \%$ MWCNT $-800^{\circ} \mathrm{C}$ & $1.88 \pm 0.17$ & 298 \\
\hline PAN- $0.5 \%$ MWCNT- $900^{\circ} \mathrm{C}$ & 0.10 & 182 \\
\hline
\end{tabular}

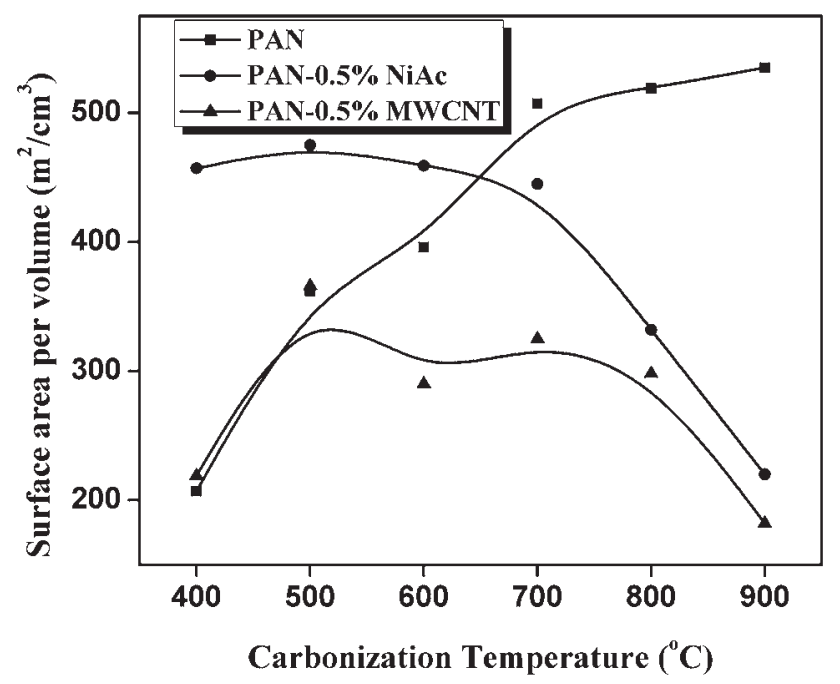

Figure 8. Surface area of PAN, PAN-0.5\% NiAc and PAN-0.5\% MWCNT-derived carbons.

area per volume as summarized in table 3. For PAN-derived carbons, $R_{\mathrm{g}}$ value gradually decreases with increasing temperature. For other catalyst added samples up to a particular temperature, $R_{\mathrm{g}}$ is first increased and then reduced with further increase in temperature.

A similar change has been observed in the values of surface area per volume, which is represented in figure 8 as the function of carbonization temperature. PAN $-900^{\circ} \mathrm{C}$ sample is having higher surface area among all PAN-derived carbon samples. These changes may be due to the inhomogeneous distribution of electron density in the carbon samples because of the dispersion of catalysts in the carbon matrix. However, an exact mechanism to explain this behaviour may be further studied separately.

\section{Conclusions}

In summary, this work demonstrates a simple approach to improve the carbon yield at low carbonization temperatures by doping the polymers with catalysts such as NiAc. The similar carbon yield as obtained with PAN $-800^{\circ} \mathrm{C}$ (no added catalyst) is achieved only at $500^{\circ} \mathrm{C}$ using PAN- $0.5 \%$ NiAC. The carbon content is also improved up to $8.7 \%$ of the polymer precursor at $900^{\circ} \mathrm{C}$ by eliminating a major amount of oxygen. However, the addition of CNT does not improve the yield of carbon but enhanced the crystallinity by ordering of graphene sheets. The similar effects of catalyst addition during pyrolysis were observed on structural properties of RF-derived carbon (data are presented in supplementary tables S1 and S2). This study suggests to adopt a low temperature catalyst-assisted pyrolysis approach without compromising the yield and quality of the final product, carbon and thus may pave the way towards a lower bound for the energy penalty during pyrolysis, in general.

\section{Acknowledgements}

CSS acknowledges financial support from SERB Young Scientist Award to carry out this work and also Indian Institute of Technology, Hyderabad, for providing necessary research facilities. RA acknowledges Y Sudhakar Reddy for his help in elemental analysis and Hyderabad Central University (Centre for Nanotechnology) for TEM analysis.

\section{References}

[1] Hirsch A 2010 Nat. Mater. 9868

[2] Falcao E HL and Wudl F 2007 J. Chem. Technol. Biotechnol. 82 524

[3] Huang Z, Zhang Y, Kotaki M and Ramakrishna S 2003 Compos. Sci. Technol. 632223

[4] Gouerec P, Talbi H, Miousse D, Tran-Van F, Dao L H and Lee K H 2001 J. Electrochem. Soc. 148 A94

[5] Tavanai H, Jalili R and Morshed M 2009 Interface Anal. 41 814

[6] Burlant W J and Parsons J L 1956 J. Polym. Sci. 22249

[7] Cho C W, Cho D, Ko Y G, Kwon O H and Kang I K 2007 Carbon Lett. 8313

[8] Rahaman M S A, Ismail A F and Mustafa A 2007 Polym. Degrad. Stab. 921421

[9] Oya A and Otani S 1979 Carbon 17131

[10] Kakunuri M, Suresh K and Sharma C S 2016 J. Anal. Appl. Pyrol. 117317

[11] Maitra T, Sharma S, Srivastava A, Cho Y-K, Madou M and Sharma A 2012 Carbon 501753 
[12] Maldonado-Hodar F J, Moreno-Castilla C, Rivera-Utrilla J, Hanzawa Y and Yamada Y 2000 Langmuir 164367

[13] Kicinski W, Bystrzejewski M, Rummeli M H and Gemming T 2014 Bull. Mater. Sci. 37141

[14] Chen Q, Jiang X, Bin Y and Matuso M 2007 Polymer J. 39568

[15] Watanabe T, Ohtsuka Y and Nishiyama Y 1994 Carbon 32329

[16] Sharma C S, Patil S, Saurabh S, Sharma A and Venkataraghavan R 2009 Bull. Mater. Sci. 32239

[17] Sharma C S, Kulkarni M M, Sharma A and Madou M 2009 Chem. Eng. Sci. 641536

[18] Al-Muhtaseb S A and Ritter J A 2003 Adv. Mater. 15101

[19] Maldonado-Hodar F J, Ferro-Garcia M A, Rivera-Utrilla J and Moreno-Castilla C 1999 Carbon 371199
[20] Kakunuri M, Vennamalla S and Sharma C S 2015 RSC Adv. 5 4747

[21] Zussman E, Chen X, Ding W, Calabri L, Dikin D A, Quintana $\mathrm{J} P$ et al 2005 Carbon 432175

[22] Ra E J, An K H, Kim K K, Jeong S Y and Lee Y H 2005 Chem. Phys. Lett. 413188

[23] Jesus J C D, González I, Quevedo A and Puerta T 2005 J. Mol. Catal. A Chem. 228283

[24] Sharma S, Sharma A, Cho Y-K and Madou M 2012 Appl. Mater. Interfaces 434

[25] Tzeng S-S 2006 Carbon 441986

[26] Mittal J, Bahl O P, Mathur R B and Sandle N K 1994 Carbon 32 1133 